\title{
ISOLATION AND CHARACTERIZATION OF WITHAFERIN-A FROM THE WITHANIA SOMNIFERA (ASHWAGANDHA)
}

\author{
*Bali Reddy Keesara, Rakesh Kumar Jat
}

Institute of Pharmacy, Shri Jagdishprasad Jhabarmal Tibrewala University Jhunjhunu Rajasthan, 313001, India

\section{ABSTRACT}

The research work is related to an improved process of isolation \& characterization of Withaferin-A from withania somnifera (Sanskrit: Ashawagandha, English: Winter cherry). Withania somnifera, commonly known as Ashwagandha, is a valued herb in Ayurvedic medicine. Roots, leaves and preparations of the plant are traditionally used as tonic, hypnotic, sedative and diuretic. $W$. somnifera mainly contains withanolides including withaferin-A which are specific to the Solanaceae family. Withanolides are biologically active secondary metabolites present in roots and leaves of W.somnifera. In the present study, we have standardized the protocol for the isolation of Withaferin-A from the Ashwagandha punchang. Withaferin A possess anti-inflammatory and anti-stress properties. This study contains newer and conventional method of isolation of Withaferin-A from Withania somnifera as well Quantitative and qualitative techniques involved in the purification of the compound was followed throughout this research work. In this study, we have taken different trials based on hydro-alcoholic solvent composition. Based on different solvent extraction process pure $98 \%$ Withaferin-A was successfully isolated.

Keywords: Withania somnifera, Withaferin-A, Isolation, TLC, HPLC.

Received 03 Jan 2017; Review Completed 29 Jan 2017; Accepted 29 Jan 2017, Available online 30 Jan 2017

Cite this article as:

Keesara BR, Jat RK, Isolation and characterization of withaferin-A from the Withania somnifera (Ashwagandha), Journal of Drug Delivery and Therapeutics. 2017; 7(1):65-69, DOI: http://dx.doi.org/10.22270/jddt.v7i1.1375

\section{INTRODUCTION:}

Since ancient times, medicinal plants have played a key role in the management of some health problems and in the discovery of new drugs ${ }^{1}$

Modern herbal medicinal science is concerned with using leading-edge technology to develop plant-derived drugs through chemistry \& Analytical techniques. This is unique way in that it combines the study of herbal medicinal science with a strong emphasis on the underlying chemistry. Medicinal chemistry is disciplines at the intersection of chemistry, especially synthetic organic chemistry, pharmacology and various other natural plants, where it is involved with design, chemical synthesis and development for market of pharmaceuticals agents. ${ }^{2,3}$

Medicinal plants are a tremendous source of raw material for the modern drug industry. Since time immemorial, plants have been extensively exploited for their therapeutic property.
The isolation of active principles of the medicinal plant is necessary for the benefits of human being. ${ }^{4}$ Whole plant or parts of plants were the main components of folk or ethanomedicine, practiced in India and other parts of the world like China, Middle East Africa and South America. Withania somnifera, also known as Ashwagandha, Indian ginseng is an important medicinal plant, which is cultivated in India for the medicinal purposes. ${ }^{3}$

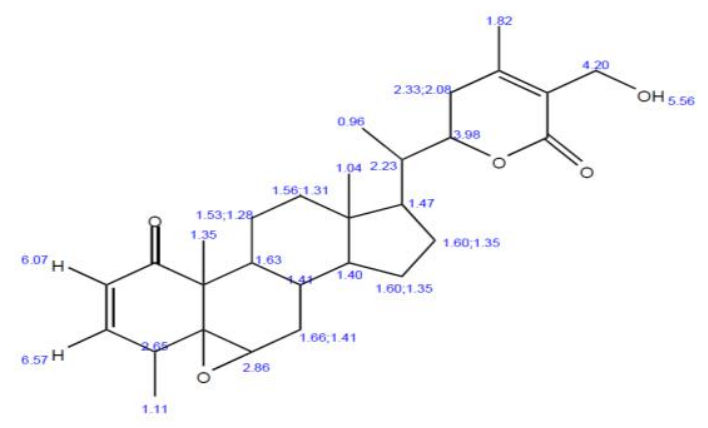

Structure of Withaniferin A 
The roots of the plant are categorized as rasayanas, which are reputed to promote health and longevity by augmenting defence against disease, arresting the ageing process, revitalizing the body in debilitated conditions, increasing the capability of the individual to resist adverse environmental factors and by creating a sense of mental well being. The roots and leaves of Ashwagandha contain various alkaloids, viz., withanolides ${ }^{5}$, withaferins ${ }^{4}$ and withanosides. ${ }^{6}$

The withanolides are steroidal compounds and bear resemblance, both in action and appearance to the active ginsenosides of Asian ginseng. Studies show that the plant has been used as an antioxidant, adaptogen, aphrodisiac, liver tonic, anti-inflammatory agent, antitumor, astringent and more recently to treat ulcers, bacterial infection, venom toxins and senile dementia. The biological activities of withanolides, especially of the dominant withanolide A and withaferin A, have been studied extensively and, more recently, have been shown to have anti-cancerous activity. 7,8

In this paper, we discussed about the purification of the secondary metabolite from the in vivo root extract of $W$. somnifera by simple techniques for the effective elution of a single compound withaferin A.

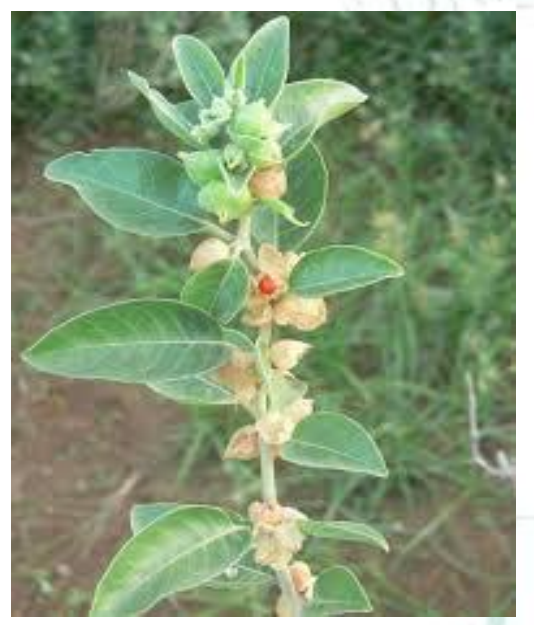

Figure 1: Withania Somnifera (Ashawgandha)

Common names - Ashawgandha, Indian Ginseng \& Indian Winter cherry

Family - Solanaceae

Biological Source - Leaves, Root of Withania Somnifera

It grows in dry parts in sub-tropical regions. Rajasthan, Punjab, Haryana, Uttar Pradesh, Gujarat, Maharashtra \& Madhya Pradesh.

\section{Active constituents are}

At present, 12 alkaloids, 35 withanolides, \& several sitoindosides from this plant have been isolated \& studied.

Mainly contains Withanolides \& Withaferin Withanolides I, II, \& III With none, Withasomnine \& Withanine

Medicinal Use: Anti-inflammatory, Analgesic, Antistress, Osteoarthritis, Immunomodulatory \& Anxiety \& Cancer

\section{MATERIALS \& METHODS:}

\section{(1) Plant material and Chemicals:}

Roots and Leaves of W. somnifera were the forest of aravali Bharathari District Rajasthan. Materials were air dried at room temperature and powdered mechanically. The powdered of roots and leaves were used as the plant material for all analysis. Chemicals, instruments, glassware used in the process were listed in table 1 and 2.

\section{(2) Isolation and Extraction:}

Isolation was carried out by using newer and conventional method. 200 gms ashwagandha punchang (root and leave) powder in to 2 Litre Round bottom flask (R.B.F.).then $750 \mathrm{ml}$ petroleum ether was added to deffate the material. It was Refluxed at $60{ }^{\circ} \mathrm{C}$ for $90 \mathrm{~min}$. after 90 min materials was filtrate and added further 800 $\mathrm{ml}$ of $75 \%$ Methanol and reflux continue for four hours at $60^{\circ} \mathrm{C}$. After that, flask was allowed to stand for cool and filtered all solutions.

About $750 \mathrm{ml}$ methanolic extract was collected, and transferred it into separation funnel.Now, extract with water $(100 \mathrm{ml})$ followed by dichloromethane $(3 \times 200 \mathrm{ml})$ and collect the lower layer separate out in to 1 liter beaker(total $600 \mathrm{ml}$ solution). Now about 8 to $10 \mathrm{gms}$ of activated charcoal were added into beaker and place beaker on water bath for $10 \mathrm{~min}$.

Then filter well by using whattmann filter paper. Yellowish color solution obtains after filtration, which allows evaporating on water bath in evaporating dish. Allowed to Complete dry it on water bath and then cool the evaporating dish for $10 \mathrm{~min}$ at room temperature. Blackish color semi solid material was obtained at bottom of the dish which was gummy in nature. Then it was washed out with $70-80 \mathrm{ml} \mathrm{n}$-hexane and shakes well the dish, allow to stand for $5 \mathrm{~min}$, then decant the nhexane in to other dish (because decanted hexane may contain powder.) Again add 70ml n-hexane in to dish which containing blackish material. Material was crushed by using mortar pastel to make dry powder. Yellowish-green powder obtains which was free flowing in nature.

Obtained yellowish free flowing powder was subjected to thin layer chromatography (TLC) for Identification, and was subjected to High performance liquid chromatography (HPLC). $\backslash$ for purification.

Table 1: List of Chemicals Used In Isolation Process

\begin{tabular}{|c|l|l|}
\hline S. $\mathbf{N}$. & \multicolumn{1}{|c|}{ Name of Chemicals } & \multicolumn{1}{|c|}{$\begin{array}{c}\text { Grade of } \\
\text { chemicals }\end{array}$} \\
\hline 1 & Petroleum ether & GR grade, Merck \\
\hline 2 & Methanol & $\begin{array}{l}\text { For synthesis, } \\
\text { Merck }\end{array}$ \\
\hline 3 & Dichloromethane & GR grade, Merck \\
\hline 4 & n-hexane & GR grade, Merck \\
\hline 5 & De-mineralized(DM) water & Extra purified \\
\hline 6 & Ethyl acetate & GR grade, Merck \\
\hline 7 & Acetone & GR grade, Merck \\
\hline 8 & Diethyl ether & GR grade, Merck \\
\hline 9 & Hydrochloric acid $(\mathrm{HCl})$ & AR grade, Merck \\
\hline 10 & Sulphuric Acid $(\mathrm{H} 2 \mathrm{SO} 4)$ & AR grade, Merck \\
\hline
\end{tabular}


Table 2: List of Chemicals Used In TLC and HPLC analysis

\begin{tabular}{|c|l|l|}
\hline S. N. & Name of Chemicals & Grade of chemicals \\
\hline 1 & Chloroform & HPLC grade, Merck \\
\hline 2 & Toluene & AR grade, Merck \\
\hline 3 & Methanol & HPLC grade, Merck \\
\hline 4 & Acetonitrile & HPLC grade, Merck \\
\hline 5 & Formic acid & AR grade, Merck \\
\hline 6 & Glacial acetic acid & AR grade, Merck \\
\hline 7 & Acetone & HPLC grade, Merck \\
\hline 8 & Ethyl acetate & AR grade, Merck \\
\hline 9 & Water for HPLC & HPLC grade, Merck \\
\hline
\end{tabular}

(3) Thin Layer chromatography: ${ }^{9,10,11}$

Thin-layer chromatography was Carry out on a precoated silica gel $60 \mathrm{~F} 254$ plate using withaferin $A$ as a reference standard. Mobile Phase: Chloroform: methanol (9.0: 1.0), Test solution: To $3 \mathrm{~g}$ of the substance being examined, add $25 \mathrm{ml}$ of methanol, heat on a water bath for 10-15 minutes, cool and filter, Standard solution: Dissolve $10 \mathrm{mg}$ of withaferin $A$ in $10 \mathrm{ml}$ of methanol, Procedure: Apply $10 \mu \mathrm{l}$ each of the test and standard solutions on a TLC plate as bands of 10 $\mathrm{mm}$. Develop the plate to a distance of $8 \mathrm{~cm}$ from the line of application. Dry the plate in air and examine under $254 \mathrm{~nm}$. Spray the plate with a solution of anisaldehyde sulphuric acid reagent (figure 1) Heat the plate at 110 Celsius for about 5 minutes till the bands are clearly visible. Results are shown in table 3

(4) High performance liquid chromatography: ${ }^{12,13,14,}$ 15

High performance liquid chromatography was performed during different trials for isolation methods.
HPLC analysis was performed on a Shimadzu LC-20AD pump system equipped with a Shimadzu SPD-20AT UV- Visible detector with the detection wavelength set at $230 \mathrm{~nm}$ and $20 \mu \mathrm{L}$ Rheodyne injector loop. A column was a reversed-phase (Luna C18 $4.6 \mathrm{~mm} \times 260 \mathrm{~mm}-$ particle size $5 \mu$ ) eluted at a rate of $1.0 \mathrm{~mL} / \mathrm{min}$ with a solvent system \{acetonitrile: $1 \%$ Glacial Acetic acid 6:4 (V/V)\}. Sample was prepared in the HPLC grade methanol. Results are shown in table 4

\section{RESULTS AND DISCUSSION:}

Withaferin-A was successfully isolated from the plant material of withania somnifera. Isolated withaferin-A was found to be above $90 \%$ pure by HPLC analysis. Isolated withaferin-A show single spot at same $\mathrm{Rf}$ value corresponding to Standard withaferin-A. Thin layer chromatography and High performance liquid chromatography was performed for identification of final compound.

Silica coated TLC is convenient and suitable for the analysis of withanolides including withaferin A. It is often used to monitor fractions or finally purified withanolides. Chloroform - methanol (95:5) is frequently used solvent system for aglycones and chloroform methanol (90:10) for glycosides.

The obtained purified compound is expected to be withaferin A, so the mobile phase for TLC of sample and standards were changed as chloroform: methanol in the ratio 9:1 with same spraying reagent. The single compounds were analyzed in TLC with standards Withaferin A. The standard withaferin-A showed the same $\mathrm{Rf}$ value as 0.65 . From this result it can be stated that the purified compound is withaferin A.

Results are shown in table 3 , and TLC chromatogram shown in below figure 1 .
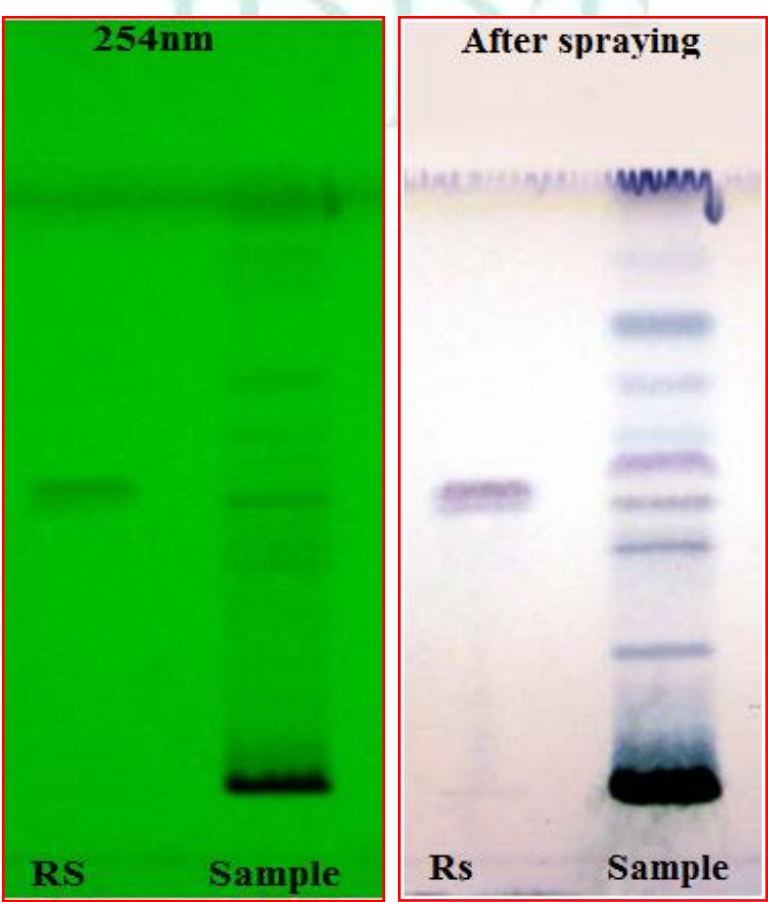

Figure 4: Thin-Layer Chromatogram of Ashwagandha RS: Withaferin A, T: Test solution (Detection by anisaldehyde sulphuric acid) 
Table 3: Results of TLC study in Rf value

\begin{tabular}{|c|c|c|c|c|}
\hline \multicolumn{2}{|c|}{$\begin{array}{c}\text { TLC Figure } \\
\text { Nnumber }\end{array}$} & \multicolumn{3}{c|}{ RF Value } \\
\cline { 3 - 5 } \multicolumn{2}{c|}{} & \multicolumn{3}{c|}{ Detection at } \\
\cline { 3 - 5 } & RS & - & $254 \mathrm{~nm}$ & After spraying \\
\hline \multirow{2}{*}{ Figure 1 } & $\mathrm{R}$ & 0.65 & 0.65 \\
& $\mathrm{~T}$ & - & $0.28,0.45,0.55,0.66,0.72$ & $0.28,0.45,0.55,0.66,0.72,0.78,0.84$ \\
\hline Figure 2 & $\mathrm{RS}$ & 0.65 & 0.65 & 0.65 \\
\cline { 2 - 5 } & $\mathrm{T}$ & 0.65 & $0.28,0.45,0.54,0.58,0.65,0.76,0.81$, & $0.28,0.45,0.58,0.65,0.76$ \\
& & & $0.82,0.84$ & \\
\hline
\end{tabular}

The purified compound was further confirmed by High Pressure Liquid Chromatography analysis with standard Withaferin A as reference compound. Both standard and purified compound obtain peak at same retention time (3.957 $\mathrm{min}$ ) as shown in figure 2 and 3 respectively. Results of HPLC analysis are shown in below table 4

Table 2: Results of HPLC study

\begin{tabular}{|c|c|c|c|c|c|c|}
\hline Sample Name & $\begin{array}{c}\text { Fig. } \\
\text { No. }\end{array}$ & $\begin{array}{c}\text { Retention } \\
\text { Time }\end{array}$ & $\begin{array}{c}\text { Peak } \\
\text { Area }\end{array}$ & $\begin{array}{c}\text { Wt/ml } \\
\text { (Mg/ml) }\end{array}$ & $\begin{array}{c}\text { Conc. } \\
\text { (ppm) }\end{array}$ & \% Purity \\
\hline Withaferin A & 3.2 & 8132.155 & 3.957 & $1 \mathrm{mg} / 10 \mathrm{ml}$ & $100 \mathrm{ppm}$ & $97.00 \%$ \\
\hline Test & 3.3 & 7753.429 & 3.957 & $1 \mathrm{mg} / 10 \mathrm{ml}$ & $100 \mathrm{ppm}$ & $92.48 \%$ \\
\hline
\end{tabular}

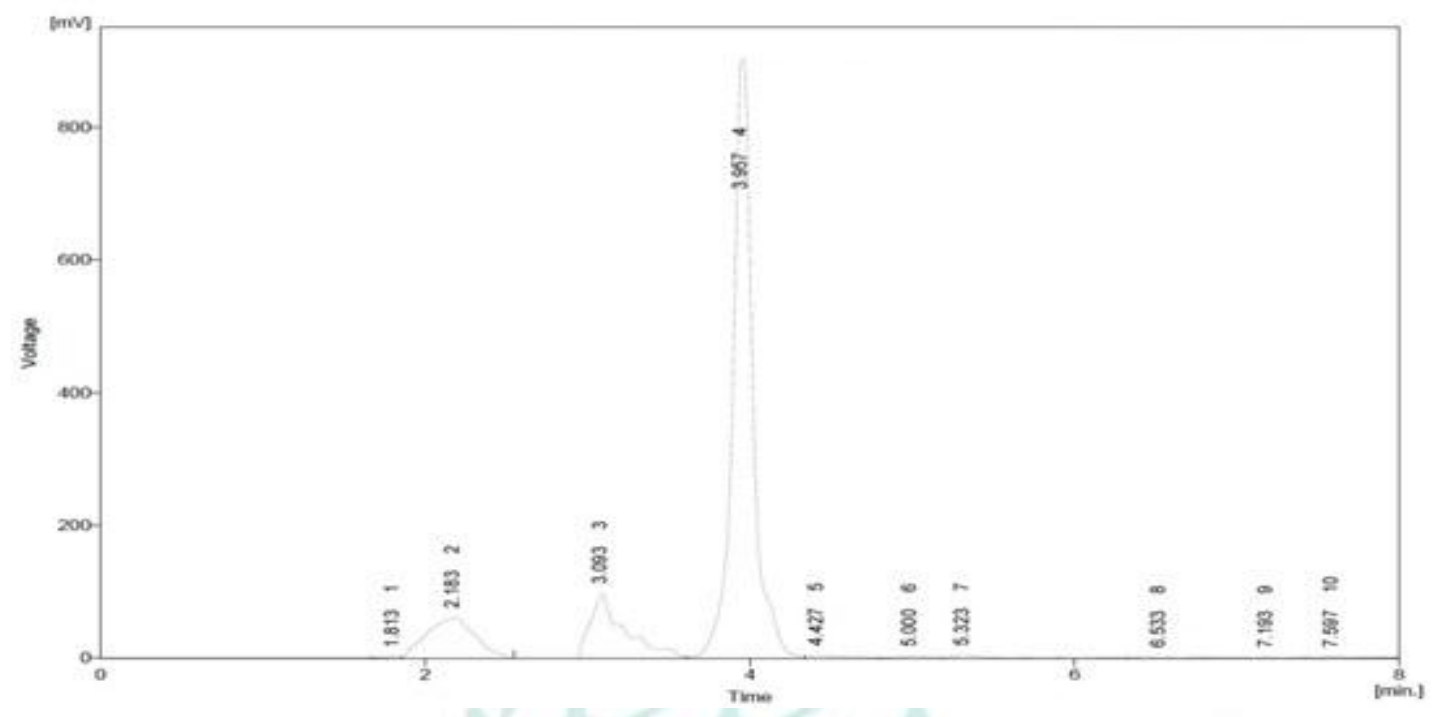

Figure 2: HPLC chromatogram of Sample Standard Withaferin A (97\%)

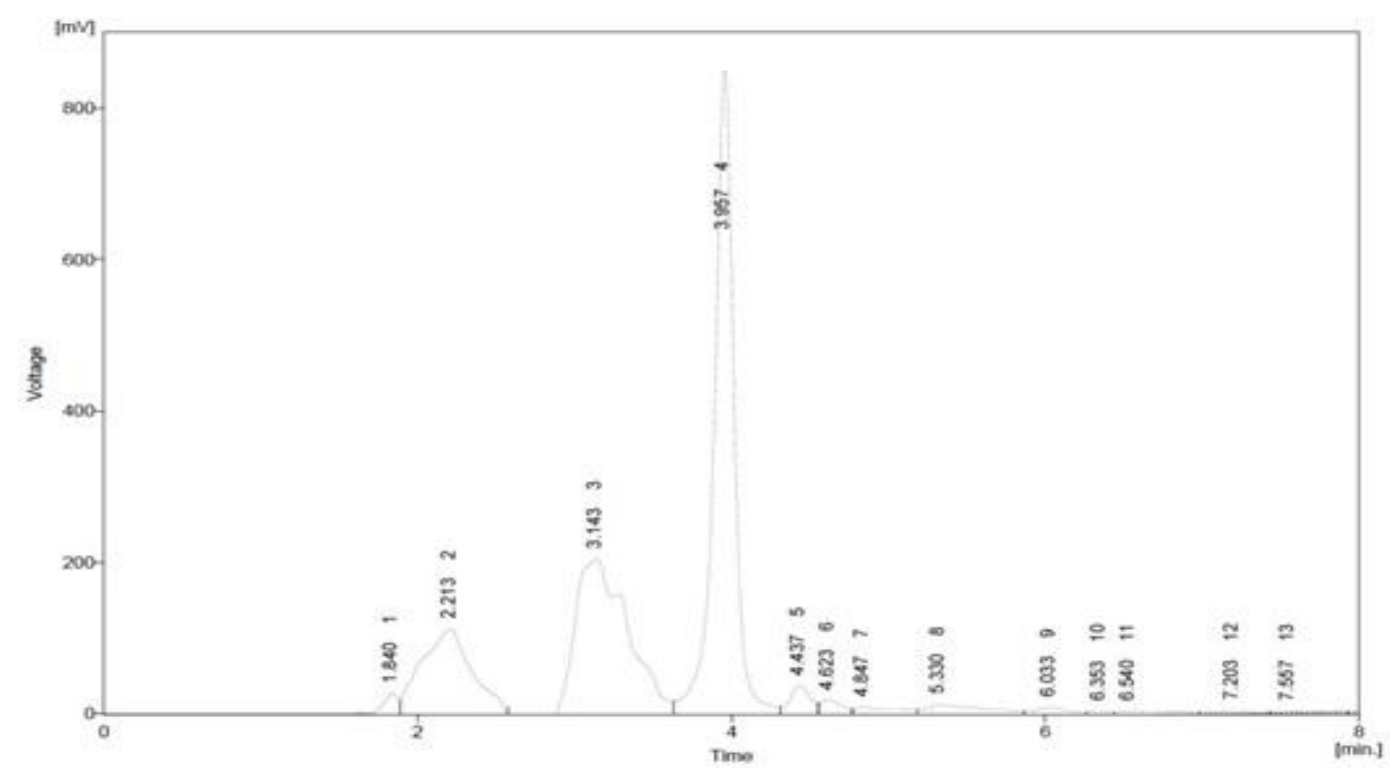

Figure 3: HPLC chromatogram of test withaferin A 


\section{CONCLUSION:}

From the present study, it can be concluded that the Withania somnifera that contain Withaferin A compound were eluted using simple techniques with less cost effect and they are quantified with the HPLC techniques. So, the obtained Withaferin A compound will be used as the marker for analyzing the unknown compounds. 500 micro gram withaferin A compound

\section{REFERENCES:}

1. "The Value of Plants Used in Traditional Medicine for Drug Discovery". Environmental Health Perspectives, Reviews in Environmental Health. 2001, 109(1).

2. Nayak S, Suryawanshi S, Vaidhun B, Microneedle technology for transdermal drug delivery: applications and combination with other enhancing techniques, Journal of Drug Delivery \& Therapeutics. 2016; 6(5):84-90. DOI: http://dx.doi.org/10.22270/jddt.v6i5.1276

3. Mukherjee PK, GMP for Indian Systems of Medicine, Business Horizons, New Delhi, 2003.

4. Boparai A, Niazi J, Bajwa N, Singh AP, A Review Update on Dillenia Indica F. Elongata (MIQ.)MIQ., Journal of Drug Delivery \& Therapeutics. 2016; 6(2):62-70. DOI: http://dx.doi.org/10.22270/jddt.v6i5.1226

5. Andrew Vickers and Catherine Zollman, "ABC of complementary medicine: Herbal medicine - Clinical review". Br Med J. 1999, 16.

6. Kalaiselvi Senthil, et al, "A simple method to purify withanolide A from the roots of Withania somnifera dunal" International Journal of Pharma and Bio Sciences; 2011; 2(2)

7. Geeta singh et al, "Antimicrobial efficacy of alkaloids of Withania somnifera (Ashwagandha) an indigenous medicinal plant against some pathogens", Journal of Pharmacy Research; 2011; 4(3):807-809.

8. Shoma Paul Nandi, et al, "Antioxidant and antimicrobial activities of aqueous extract of Withania somnifera against methicillin-resistant Staphylococcus aureus", Journal of obtains approximately from the 200 grams of the dried roots of Withania somnifera.

\section{ACKNOWLEDGMENT:}

The author thankful to Suresh choudhary for providing opportunity of research work, providing necessary chemicals, instruments and additional help for free of cost.

Microbiology and Biotechnology Research, J. Microbiol. Biotech. Res; 2011, 1 (1): 40-45.

9. Zaved Ahmed Khan, et al, "L-Arginine abolishes the anxiolytic-like effect of withaferin A in the elevated plusmaze test in rats", African Journal of Pharmacy and Pharmacology. 2011; 5(2):234-237.

10. B. Bhosale et al, "HPLC Methods of medicinally important plants: a review”, Imperial J. Pharmacognosy \& Natural Products. 2011; 1(1).

11. A. Singh, et al, "Effect of time on extraction of ashwagandha in various hydro alcoholic compositions and their antiinflammatory activity", international journal of green pharmacy; January-march 2011; 69-74.

12. R. Kushwaha, et al, "Standardization of Ashwagandharishta formulation by TLC Method", International Journal of ChemTech Research, July-Sept 2011; 3(3):1033-1036,

13. S. Verma, et al, "Therapeutic uses of withania somnifera (ashwagandha) with a note on withanolides and its pharmacological actions", Asian Journal of Pharmaceutical and Clinical Research; 2011; 4(Supply 1).

14. V. Sharma, et al, "Withania somnifera: A Rejuvenating Ayurvedic Medicinal Herb for the Treatment of various Human ailments", International Journal of PharmTech Research; 2011; 3(1):187-192.

15. Z.A. Khan, et al, "Possible binding modes of withaferin-A and its analogs in the active site of NNOS molecular docking studies", International Journal of Pharma and Bio Sciences; 2011; 2(3). 